\section{Photoperiod Improves Long-term Survival of In Vitro-stored Strawberry Plantlets}

\author{
Barbara M. Reed ${ }^{1}$ \\ U.S. Department of Agriculture, Agricultural Research Service, National \\ Clonal Germplasm Repository, 33447 Peoria Road, Corvallis, OR 97333-2521
}

Additional index words. benzyladenine, cold acclimatization, cold storage, Fragaria sp., germplasm, micropropagation

\begin{abstract}
Cold storage is important for managing in vitro germplasm collections. Strawberry shoot cultures can typically be held at $4{ }^{\circ} \mathrm{C}$ for 9 to 24 months before they require repropagation. Concentration of $\mathrm{BA}$ in the storage medium, pre-storage cold acclimatization (CA), and exposure to a photoperiod during storage were studied to determine conditions for improved strawberry culture storage. Fragaria shoot cultures stored at $4{ }^{\circ} \mathrm{C}$ were rated for plantlet condition on a $0-5$ scale at 9, 12, and 19 months. Four species were CA and stored on medium with $0,1,2.5$, or $5 \mu \mathrm{M}$ BA either in darkness or under a 12-hour photoperiod. Mean ratings over all treatments and genotypes were best at 9 and 12 months (3.4) and declined at 19 months (2.2). BA in the storage medium significantly improved ratings for two species at 9 and 12 months, but ratings were not significantly different at 19 months. At 19 months of storage, shoot cultures stored with a photoperiod were rated significantly better $(P \leq 0.05)$ than those grown in darkness. Five $F$ ragaria genotypes stored on medium without BA were used to study the effect of photoperiod and CA on ratings of stored plantlets. CA-shoot cultures stored for 9 or 12 months were rated significantly better than non-CA cultures. After 12 and 19 months storage, three of the five genotypes stored under a 12-hour photoperiod had significantly higher ratings than those stored in the dark $(P \leq 0.01)$, but by 19 months $C A$ was nonsignificant. Overall, the addition of a photoperiod improved the condition of Fragaria shoot cultures stored at $4{ }^{\circ} \mathrm{C}$. Chemical name used: $N^{6}$-benzyladenine (BA).
\end{abstract}

Strawberries are stored as in vitro plantlets for plant breeding, as virus-free planting stock, and for germplasm preservation (Mullin and Schlegel, 1976; Reed and Hummer, 1995). Medium-term (3 months to 4 years) storage for in vitro cultures of temperate genera is typically at 4 or $5^{\circ} \mathrm{C}$ in darkness (Marino et al., 1985; Reed, 1992; Wilkins et al., 1988), although some are stored under a photoperiod (Reed, 1993a; Wanas et al., 1986). Fragaria in vitro storage was initiated in the 1970 s with studies on medium, illumination, and temperature (Boxus, 1976). Storage of shoot cultures on filter paper bridges in liquid medium at $4{ }^{\circ} \mathrm{C}$ in the dark with additional medium added at 3-month intervals is successful for many commercial strawberry genotypes (Mullin and Schlegel, 1976). Strawberry cultures are stored for many years on a semisolid basal medium at low temperature with annual transfers for rejuvenation (Jungnickel, 1988). Cold storage of Fragaria germplasm in semipermeable plastic tissueculture bags ranges from 9-24 months be-

\footnotetext{
Received for publication 22 Mar. 2001. Accepted for publication 16 Oct. 2001. This research was supported by ARS CRIS 5853-21000-026-00D. The technical assistance of Carolyn Paynter is greatly appreciated. Use of trade names in this publication does not imply endorsement of the U.S. Dept. of Agriculture (USDA).

'E-mail address: reedbm@bcc.orst.edu
}

tween transfers, with an average storage interval of 15 months (Reed, 1991). Contamination of stored cultures is greatly reduced when cultures are stored in sealed plastic tissue-culture bags (Reed, 1992).

Studies show that light is important for preserving photosynthetic capabilities and maintaining dry weight of broccoli (Brassica oleracea L.) seedlings grown under photoautotrophic conditions and stored for 4-6 weeks at low temperatures (Kubota and Kozai, 1994). Light levels higher than the light compensation point $\left(2-3 \mu \mathrm{mol} \cdot \mathrm{m}^{-2} \cdot \mathrm{s}^{-1}\right)$ stimulate shoot elongation during storage. Low temperatures $\left(5^{\circ} \mathrm{C}\right)$ and a photoperiod $(16-\mathrm{h}$ at $\left.2 \mu \mathrm{mol} \cdot \mathrm{m}^{-2} \cdot \mathrm{s}^{-1}\right)$ of white light are essential for maintaining dry weight and maintaining short internodes in broccoli during low-temperature storage (Kubota et al., 1996). Prunus shoots stored for 10 months have better survival with a 16 -h photoperiod at 4 or $8{ }^{\circ} \mathrm{C}$, than in darkness, but store better in darkness at $-3{ }^{\circ} \mathrm{C}$ (Marino et al., 1985).

Variation among genotypes for optimal storage conditions adds to the complexity of storing in vitro Fragaria germplasm collections. The effects of growth regulators, photoperiod, and cold acclimatization (CA) on the health of shoot cultures in cold storage were examined in this study. Two main questions were asked. Does the BA concentration in the medium or growth under a photoperiod improve or help maintain healthy cultures of cold-stored Fragaria germplasm? Is CA, with or without a photoperiod, effective in maintaining healthy cold-stored Fragaria germplasm?

\section{Materials and Methods}

Cultures were grown in Magenta $\mathrm{GA}_{7}$ culture vessels (Magenta Corp., Chicago) on 40 mL NCGR-FRA medium (Reed, 1991), at $25^{\circ} \mathrm{C}$ under a 16-h light/8-h dark photoperiod $\left(25 \mu \mathrm{mol} \cdot \mathrm{m}^{-2} \cdot \mathrm{s}^{-1}\right)$ from cool-white fluorescent bulbs with a 3 -week transfer interval. All media were dispensed into containers prior to autoclaving. Plantlets $(2-3 \mathrm{~cm}$ tall $)$ were transferred to semipermeable tissue-culture bags (Star-pak, Garner Enterprises, Willis, Texas) with $10 \mathrm{~mL}$ medium per chamber 3 weeks after the last subculture. Sealed cultures were grown for 1 week in the growth room (GR), and then for 1 week under CA conditions [22 ${ }^{\circ} \mathrm{C}, 8$-h light $\left(10 \mu \mathrm{mol} \cdot \mathrm{m}^{-2} \cdot \mathrm{s}^{-1}\right)$ and $-1{ }^{\circ} \mathrm{C}, 16$ $\mathrm{h}$ dark before storage] (Angelo et al., 1939). Ten plantlets of each accession were stored, each in an individual section $(15 \times 150 \mathrm{~mm})$ of a five-section bag. A firmer medium [3\% Bitek agar (Difco, Detroit,) and $0.15 \%$ Gelrite (Schweitzer-Hall, South Plainfield, N.J.)] compared to that in boxes was used in the bags to compensate for the low level of water loss through the bag walls (Reed, 1991).

Expt. 1. Influence of BA concentration and photoperiod on cold storage of Fragaria germplasm. Four accessions of Fragaria were tested: $F$. vesca L. (local identifying number 955.001), F . virginiana Duchesne (440.001), F. moschata Duchesne cv. Capron (117.001), F. chiloensis (L.) Duchesne (50.001), based on data from an earlier study (Reed, 1991). Treatments included a control and three BA concentrations $(1,2.5,5 \mu \mathrm{M})$ and storage under either a 12 -h photoperiod $\left(3 \mu \mathrm{mol} \cdot \mathrm{m}^{-2} \cdot \mathrm{s}^{-1}\right)$ or total darkness at $4{ }^{\circ} \mathrm{C}$. Replications: two bags (10 plantlets) per treatment per accession. The experiment was set up as a split-split plot with $N^{6}$-benzyladenine (BA) concentration as the main plot with photoperiod as a subplot and genotype as a subplot of photoperiod.

Expt. 2. Influence of CA and photoperiod on cold-stored germplasm. Five accessions of Fragaria were evaluated: F. Xananassa cultivars Fresno (2.001), Pocahontas (136.001), F. chiloensis (49.001), F. vesca (956.001), F. virginiana (548.001), also chosen based on earlier data (Reed, 1991). The storage medium lacked BA. Treatments were either standard CA ( 1 week in GR +1 week CA) or 2 weeks in GR. Two bags (10 plantlets) were tested per treatment for each accession and stored either in total darkness or under a 12-h photoperiod at $4{ }^{\circ} \mathrm{C}$. The experiment was a split-split plot with cold acclimatization as the main plot with photoperiod as a subplot and genotype as a subplot of photoperiod.

Evaluation. Data were taken at 9,12, and 19 months. Each plantlet was rated on a $0-5$ scale. Ratings were: $5=$ dark green leaves and stems, no etiolation, base green; $4=$ green leaves and stems, little etiolation; $3=$ shoot tips and upper leaves green, etiolation present, base green; 2 = shoot tip green, leaves and 
stems mostly brown, base may be brown; $1=$ plantlet mostly brown, only extreme shoot tip green, much of base dark brown; and $0=$ all of plantlet brown, no visible green on shoot tip, dead. Data were evaluated by analysis of variance (ANOVA) and the FACTOR program on MSTATC (Michigan State Univ.).

\section{Results and Discussion}

Influence of BA concentration and photoperiod on cold storage of Fragaria germplasm. Plant condition ratings remained high at the 9 and 12 month rating periods and then declined greatly at 19 months (Fig. 1). At 9 months BA concentration, photoperiod and genotype and the two-way interactions were all significant $(P \leq 0.05)$ (Table 1$)$. Cultures stored with a photoperiod on medium with 0 or $5 \mu \mathrm{M}$ BA were rated significantly higher than those stored in the dark, while cultures on 1 and $2.5 \mu \mathrm{M} \mathrm{BA}$ had similar ratings in both storage conditions (Fig. 2A). The genotype $\times$ BA interactions were evident as well $(P \leq 0.05)$ (Fig. 2B). Stored $F$. chiloensis shoots were rated significantly higher on 1 and $5 \mu \mathrm{M}$ BA than those without BA. F. vesca shoot ratings were significantly higher for plants stored on $2.5 \mu \mathrm{M}$ BA than those on the lower concentrations but not different from 5 $\mu$ M. Fragaria virginiana and $F$. moschata shoots had similar ratings on all BA concentrations. Genotype $\times$ photoperiod interaction was significant $(P \leq 0.05)$ because the darkstored $F$. vesca shoot ratings were significantly greater than those of the dark-stored $F$. virginiana, the $F$. chiloensis shoots stored under a photoperiod, and both $F$. moschata treatments (Fig. 2C). There were no significant differences within any of the genotypes for photoperiod treatment.

At 12 months, photoperiod was a significant factor $(P \leq 0.05)$ and the interaction of BA $\times$ genotype was also significant $(P \leq$ 0.05 ) (Table 1). Cultures stored with a photoperiod were rated 3.5 while those in the dark were 3.4. The addition of BA to the storage medium was significant $(P \leq 0.05)$ for both $F$. chiloensis and $F$. vesca but not for the other species (Fig. 2D).

At 19 months of storage, only photoperiod and genotype were significant factors (Table 1). Shoot cultures stored under a photoperiod were rated significantly higher $(P \leq 0.05)$ than those in the dark (2.3 vs. 2.1). Fragaria vesca ratings $(2.1)$ were significantly $(P \leq 0.01)$ lower than those of the other species (2.2 to 2.5) by 19 months.

Influence of CA and photoperiod on coldstored germplasm. Great variation was evident for the five genotypes studied (Table 2) (Fig. 3). The three-way interaction of $\mathrm{CA} \times$ photoperiod $\times$ genotype was significant at 9 months (Fig. 4A). 'Fresno' CA shoots stored under a photoperiod were rated significantly higher $(P \leq 0.05)$ than the dark-stored cultures, but were not significantly higher than the RT cultures stored under a photoperiod. Fragaria chiloensis stored significantly better with RT treatment and a photoperiod, while $F$. virginiana was best with CA and a photope-

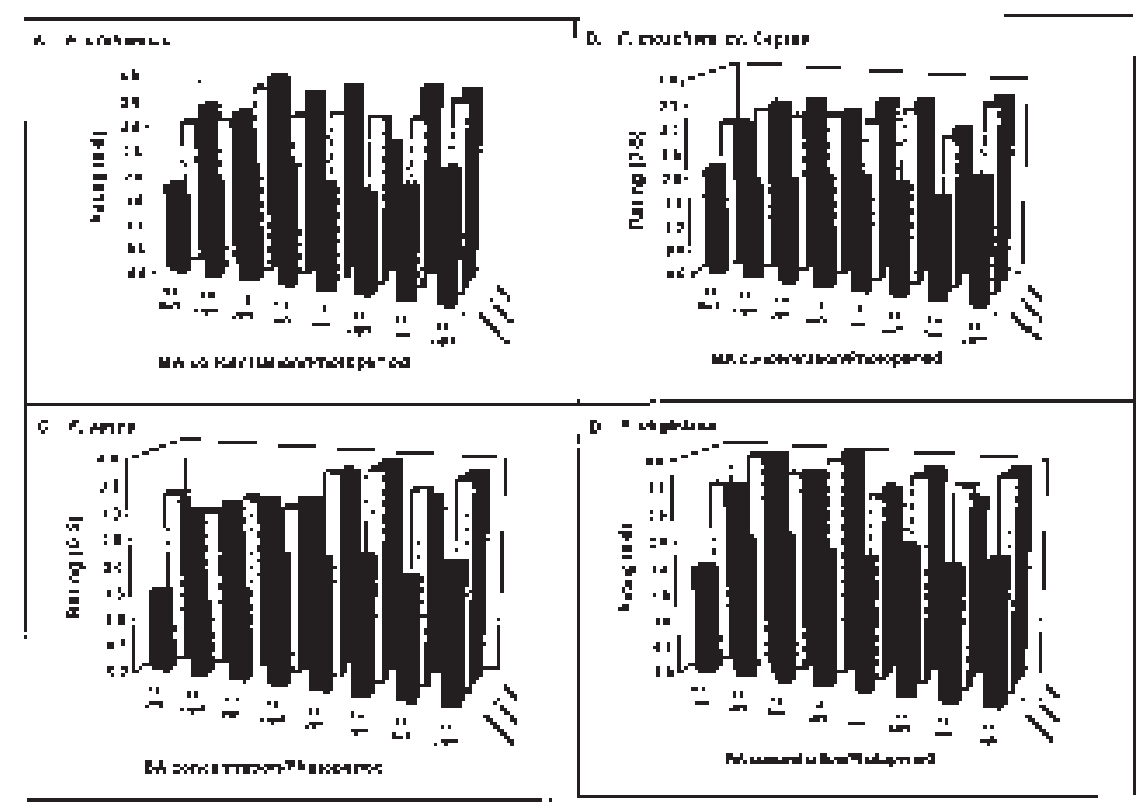

Fig. 1. Condition ratings of four Fragaria species stored at $4{ }^{\circ} \mathrm{C}$ on medium with four benzyladenine (BA) concentrations $(\mu \mathrm{M})$ in darkness or under a 12-h photoperiod. Cultures were rated on a 0-5 scale (dead to dark green) after 9,12 , and 19 months of storage.

Table 1. Analysis of variance of condition rating means for data taken at 9, 12, or 19 months from four Fragaria genotypes cold acclimatized and stored on medium with four benzyladenine (BA) concentrations at $4{ }^{\circ} \mathrm{C}$ in darkness or under a 12 -h photoperiod.

\begin{tabular}{|c|c|c|c|c|c|c|c|}
\hline \multirow[b]{3}{*}{ Source } & \multirow[b]{3}{*}{ DF } & \multicolumn{6}{|c|}{ Months stored } \\
\hline & & \multicolumn{2}{|r|}{9} & \multicolumn{2}{|r|}{12} & \multicolumn{2}{|r|}{19} \\
\hline & & MS & Significance & MS & Significance & MS & Significance \\
\hline Replication & 1 & 0.00 & & 0.00 & & 0.01 & \\
\hline BA concentration $(\mathrm{B})$ & 3 & 0.68 & $*$ & 0.43 & $*$ & 0.73 & NS \\
\hline Error & 3 & 0.03 & & 0.03 & & 0.11 & \\
\hline Photoperiod (P) & 1 & 0.42 & $*$ & 0.49 & $*$ & 0.44 & $*$ \\
\hline $\mathrm{B} \times \mathrm{P}$ & 3 & 0.29 & $*$ & 0.12 & NS & 0.08 & NS \\
\hline Error & 4 & 0.03 & & 0.03 & & 0.03 & \\
\hline Genotype (G) & 3 & 0.41 & $*$ & 0.72 & $* * *$ & 0.53 & $* *$ \\
\hline $\mathrm{B} \times \mathrm{G}$ & 9 & 0.29 & $*$ & 0.18 & $*$ & 0.18 & NS \\
\hline $\mathrm{P} \times \mathrm{G}$ & 3 & 0.58 & $* *$ & 0.18 & NS & 0.03 & NS \\
\hline $\mathrm{B} \times \mathrm{P} \times \mathrm{G}$ & 9 & 0.06 & NS & 0.05 & NS & 0.10 & NS \\
\hline Error & 24 & 0.09 & & 0.07 & & 0.1 & \\
\hline Total & 63 & & & & & & \\
\hline
\end{tabular}

Ns, ${ }^{*},{ }^{* *},{ }^{* * *}$ Nonsignificant or significant at $P \leq 0.05,0.01$, or 0.001 , respectively.

riod. 'Pocahontas' cultures CA and stored under a photoperiod were significantly better than RT-treated culture, but not the CA, darkstored cultures. Fragaria vesca CA, darkstored shoots were rated significantly lower than either of the cultures stored under a photoperiod.

At 12 months culture, cold acclimatization was significant $(P \geq 0.05)$ and the photoperiod $\times$ genotype interaction was highly significant $(P \geq 0.001)$ (Table 2). CA shoots were rated 3.1 compared to 2.6 for RT shoots. 'Fresno', $F$. chiloensis, and $F$. virginiana stored significantly better under a photoperiod than in the dark, while the remaining cultures were not significantly different between the two storage conditions (Fig. 4B). The 19-month stored cultures retained the significant $(P \geq 0.01)$ photoperiod $\times$ genotype interaction (Table 2 ) for the same three genotypes (Fig. 4B). 'Pocahontas' and $F$. vesca ratings did not differ significantly between the storage conditions at either 12 or 19 months.
Standard storage procedures at NCGR mandate removal from storage and repropagation for cultures rated 2 or less, so all nine accessions in this study would probably be repropagated at 18-22 months. Photoperiod was important for maintaining higher ratings at the longest storage interval ( 19 months) in both experiments, as in many other genera. The effect of photoperiod on cold-stored cultures is dependent on the genus; some plantlets, like Pyrus and Rubus, store best under a photoperiod (Oka and Niino, 1997; Reed, 1993b, 1999b; Reed and Chang, 1997). Others, such as Populus, Prunus, and some Fragaria, do better without light (Hausman et al., 1994; Marino et al., 1985; Mullin and Schlegel, 1976). A study of four mint (Mentha L.) genotypes showed that shoot cultures stored for 24 months rated as well or better with a photoperiod at $4{ }^{\circ} \mathrm{C}$ as those stored in the dark (Reed, 1999b). Most raspberry and blackberry shoot cultures (Rubus L.) stored with a photoperiod for 30 months were rated as good or 


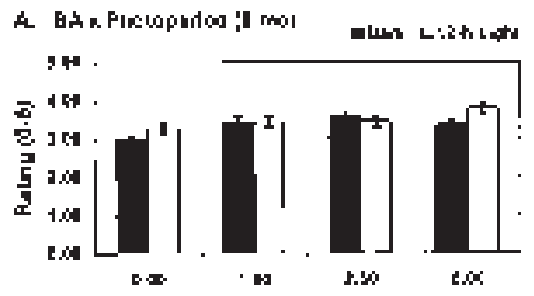

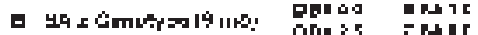

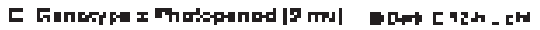
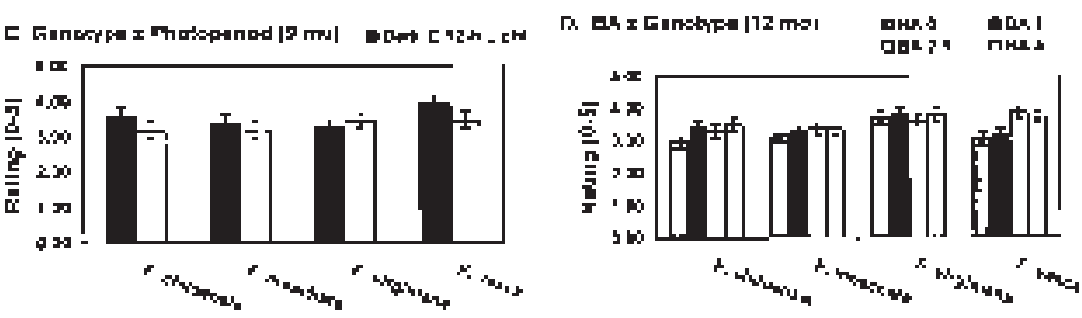

Fig. 2. Condition ratings for shoot cultures of four Fragaria species stored at $4{ }^{\circ} \mathrm{C}$ as influenced by benzyladenine (BA), photoperiod, and genotype interactions. A) The interaction of BA concentration $(\mu \mathrm{M})$ and photoperiod at 9 months. B) The interaction of BA $(\mu \mathrm{M})$ and genotype at 9 months. C) The interaction of genotype and photoperiod at 9 months. D) The interaction of BA $(\mu \mathrm{M}) \times$ genotype at 12 months. Scale as in Fig. 1.

Table 2. ANOVA of condition rating means taken at 9, 12, or 19 months from five Fragaria genotypes cold acclimatized (CA) or grown at room temperature (RT) before storage on medium without benzyladenine at $4{ }^{\circ} \mathrm{C}$ in darkness or under a 12 -h photoperiod.

\begin{tabular}{|c|c|c|c|c|c|c|c|}
\hline \multirow[b]{3}{*}{ Source } & \multirow[b]{3}{*}{ DF } & \multicolumn{6}{|c|}{ Months stored } \\
\hline & & \multicolumn{2}{|r|}{9} & \multicolumn{2}{|r|}{12} & \multicolumn{2}{|r|}{19} \\
\hline & & MS & Significance & MS & Significance & MS & $\overline{\text { Significance }}$ \\
\hline Replication & 1 & 0.03 & & 0.08 & & 0.05 & \\
\hline Acclimatization (A) & 1 & 0.08 & NS & 2.81 & $*$ & 0.84 & NS \\
\hline Error & 1 & 0.00 & & 0.01 & & 0.0 & \\
\hline Photoperiod (P) & 1 & 3.48 & $* *$ & 5.63 & $* *$ & 4.49 & NS \\
\hline $\mathrm{A} \times \mathrm{P}$ & 1 & 0.53 & $*$ & 0.01 & NS & 0.03 & NS \\
\hline Error & 2 & 0.03 & & 0.04 & & 0.18 & \\
\hline Genotype (G) & 4 & 0.89 & $* * *$ & 1.31 & $* * *$ & 0.27 & NS \\
\hline$A \times G$ & 4 & 0.39 & $* * *$ & 0.31 & NS & 0.10 & NS \\
\hline$P \times G$ & 4 & 0.24 & $* *$ & 1.8 & $* * *$ & 0.63 & $* *$ \\
\hline$A \times P \times G$ & 4 & 0.19 & $*$ & 0.36 & NS & 0.03 & NS \\
\hline Error & 16 & 0.04 & & 0.16 & & 0.13 & \\
\hline Total & 39 & & & & & & \\
\hline
\end{tabular}

Ns, *,**,*** Nonsignificant, or significant at $P \leq 0.05,0.01$, or 0.001 , respectively.

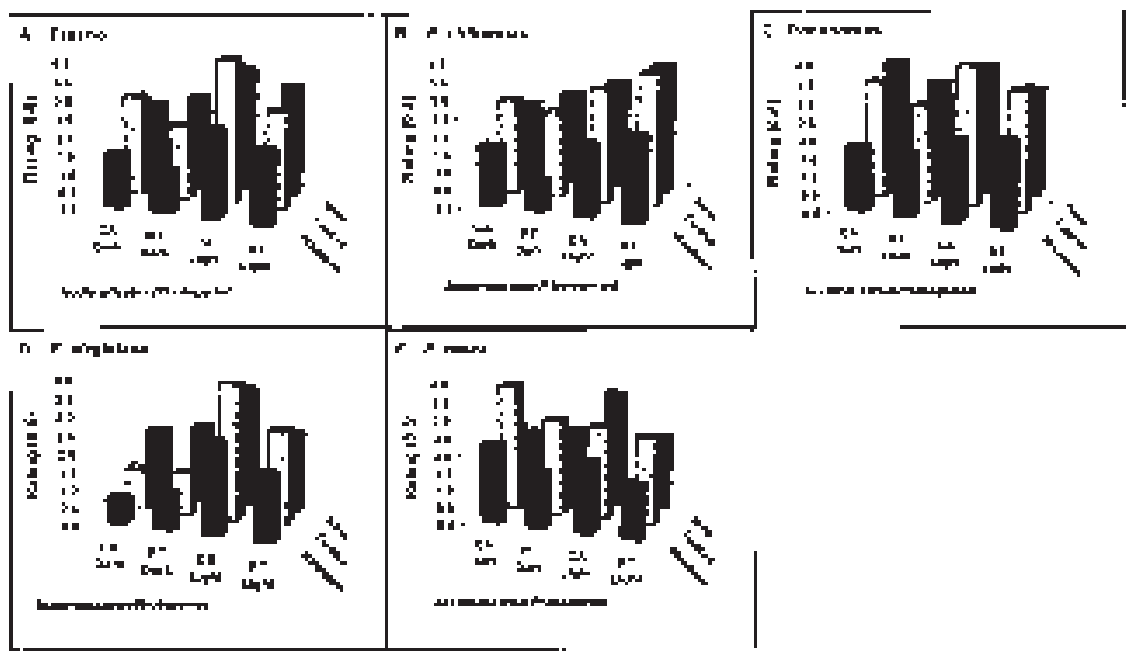

Fig. 3. Condition ratings of shoot cultures of five Fragaria genotypes preconditioned at room temperature (RT) or cold acclimatized (CA) and stored at $4{ }^{\circ} \mathrm{C}$ in darkness (Dark) or under a 12 -h photoperiod (Light). Scale as in Fig. 1. better than those grown in darkness (Reed, 1993a). Marino et al. (1985) found that a photoperiod was beneficial for Prunus germplasm at $4{ }^{\circ} \mathrm{C}$ but was detrimental at $-3{ }^{\circ} \mathrm{C}$; however, Hausman et al. (1994) determined that photoperiod was nonsignificant for survival of in vitro-stored poplar (Populus L.) plantlets. Broccoli and hosta (Hosta tokudama F. Maekawa) seedlings stored for 4-6 weeks under a photoperiod had increased fresh weight, more chlorophyll, and shorter internodes than those stored in the dark; however, these plantlets were cultured under photoautotrophic conditions. Even slight increases in condition ratings for Fragaria shoots stored for 19 months with a photoperiod could lengthen the storage period by 3-4 months. Increased storage time can have important consequences for management of large in vitro collections. Spreading repropagation over a longer time period allows for a more even repropagation cycle and results in less strain on personnel and resources.

In this study, two of the four Fragaria species responded positively to increased BA concentrations in the storage medium, while the other two species were not affected (Fig. 2 $\mathrm{B}$ and $\mathrm{D})$. These differences were nonsignificant for 19-month stored shoots, and thus BA cannot be considered important for improving the length of Fragaria in in vitro storage. Hausman et al. (1994) also determined that cytokinin-containing storage medium was no more effective than cytokinin-free medium for storage of poplar shoots.

CA is important in the development of cold tolerance in many plant types, especially those from temperate climates (Warren, 1998; Weiser, 1970). CA of in vitro-grown plants is critical for some cryopreservation protocols (Chang and Reed, 1997, 1999, 2000; Reed, 1988, 1993b; Vandenbussche and De Proft, 1998). One week of CA can greatly increase the cold hardiness of in vitro-grown Pyrus shoots, resulting in better recovery following cryopreservation (Chang and Reed, 2000). We had anticipated that CA would have a positive impact on the tolerance of Fragaria shoots to cold temperatures and therefore increased the length of storage. Acclimatization did have a positive impact on two genotypes at 12 months; however, by 19 months there were no significant differences for any of the cultures. The cold hardiness of these cultures was not tested, and further studies are needed to determine the mechanism of this response.

Photoperiod, BA, and $\mathrm{CA}$ all resulted in improved ratings for some of the in vitrostored Fragaria plantlets at the three test periods, but only photoperiod was important at 19 months of storage. The intended use of stored Fragaria plants should be considered in analyzing these results. Laboratories requiring 9 or 12 month storage would have healthier plants if they stored acclimatized shoots on medium with BA under a photoperiod. The results from this study show that neither BA nor CA contributed to improved plant condition by 19 months, but photoperiod was significantly better for many genotypes. In vitro storage of plant germplasm requires general- 


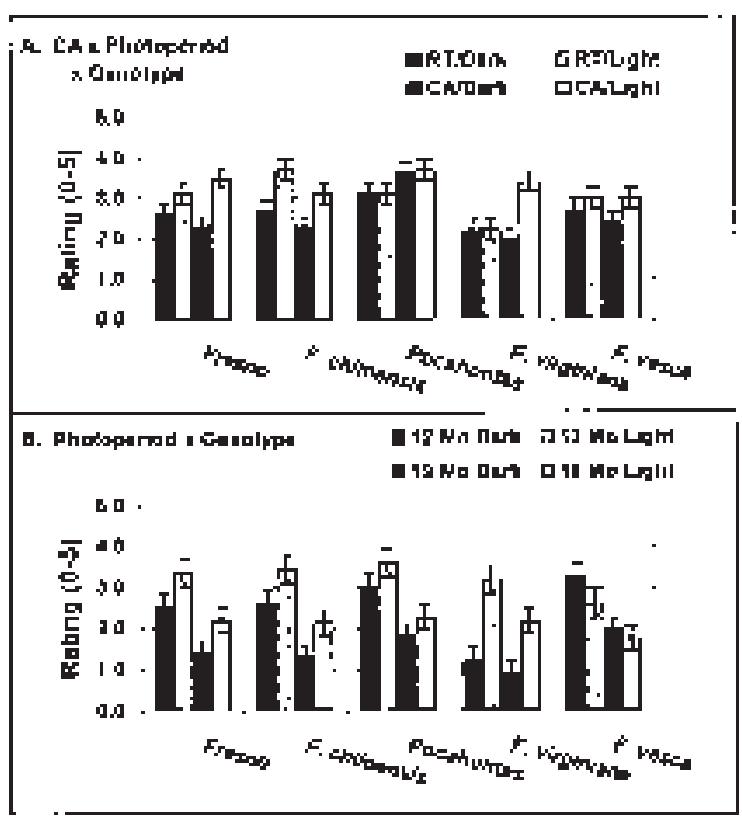

Fig. 4. Condition ratings of shoot cultures of five Fragaria genotypes preconditioned at room temperature (RT) or cold acclimatized (CA) and stored at $4{ }^{\circ} \mathrm{C}$ in darkness or under a 12 -h photoperiod. Cultures were rated on a $0-5$ scale (dead to dark green). (A) The $\mathrm{CA} \times$ photoperiod $\times$ genotype interaction at 9 months. (B) The photoperiod $\times$ genotype interactions after 12 and 19 months. Scale as in Fig. 1 .

ized treatments suitable for many genotypes. The Fragaria germplasm collection at the U.S. Dept. of Agriculture, Agricultural Research Service, National Clonal Germplasm Repository, Corvallis, includes in vitro storage of 300 or more genotypes (Reed, 1999a). This diverse collection is currently stored at $4{ }^{\circ} \mathrm{C}$ as CA plantlets in semipermeable plastic tissue-culture bags on medium without BA and under a 12-h photoperiod. The results of this study indicate that the present storage protocol should be maintained to keep the shoot cultures in good condition for the longest possible time.

\section{Literature Cited}

Angelo, E., V.E. Iverson, and W.G. Brierley. 1939. Studies on some factors relating to hardiness in the strawberry. Minnesota Tech. Bul. 135:1-36.

Boxus, P. 1976. Production of virus-free strawberry by in vitro culture. Acta Hort. 66:35-38.

Chang, Y. and B.M. Reed. 1997. The effects of in vitro-growth condition on the cryopreservation of Pyrus meristems. In Vitro Cell. Dev. Biol. 33:50A.
Chang, Y. and B.M. Reed. 1999. Extended cold acclimation and recovery medium alteration improve regrowth of Rubus shoot tips following cryopreservation. Cryo-Lett. 20:371-376.

Chang, Y. and B.M. Reed. 2000. Extended alternating-temperature cold acclimation and culture duration improve pear shoot cryopreservation. Cryobiology 40:311-322.

Hausman, J.-F., O. Neys, C. Kevers, and T. Gaspar. 1994. Effect of in vitro storage at $4{ }^{\circ} \mathrm{C}$ on survival and proliferation of poplar shoots. Plant Cell Tiss. Org. Cult. 38:65-67.

Jungnickel, F. 1988. Strawberries (Fragaria spp. and hybrids), p. 38-103. In: Y.P.S. Bajaj (ed.). Biotechnology in agriculture and forestry, Vol. 6. Springer-Verlag, Berlin.

Kubota, C. and T. Kozai. 1994. Low-temperature storage for quality preservation and growth suppression of broccoli plantlets cultures in vitro. HortScience 29:1191-1194.

Kubota, C., N.C. Rajapakse, and R.E. Young. 1996. Low-temperature storage of micropropagated plantlets under selected light environments. HortScience 31:449-452.

Marino, G., P. Rosati, and F. Sagrati. 1985. Storage of in vitro cultures of Prunus rootstocks. Plant
Cell Tiss. Org. Cult. 5:73-78.

Mullin, R.H. and D.E. Schlegel. 1976. Cold storage maintenance of strawberry meristem plantlets. HortScience 11:100-101.

Oka, S. and T. Niino. 1997. Long term storage of pear (Pyrus sp.) shoot cultures in vitro by minimal growth method. Jpn. Agr. Res. Quart. 31:1-7.

Reed, B.M. 1988. Cold acclimation as a method to improve survival of cryopreserved Rubus meristems. Cryo-Lett. 9:166-171.

Reed, B.M. 1991. Application of gas-permeable bags for in vitro cold storage of strawberry germplasm. Plant Cell Rep. 10:431-434.

Reed, B.M. 1992. Cold storage of strawberries in vitro: A comparison of three storage systems. Fruit Var. J. 46:98-102.

Reed, B.M. 1993a. Improved survival of in vitrostored Rubus germplasm. J. Amer. Soc. Hort. Sci. 118:890-895.

Reed, B.M. 1993b. Responses to ABA and cold acclimation are genotype dependent for cryopreserved blackberry and raspberry meristems. Cryobiology 30:179-184.

Reed, B.M. 1999a. The in vitro genebank of temperate fruit and nut crops at the National Clonal Germplasm Repository-Corvallis, p. 132-135. In: F. Engelmann (ed.). Management of field and in vitro germplasm collections. Intl. Plant Genetic Resources Inst., Rome.

Reed, B.M. 1999b. In vitro storage conditions for mint germplasm. HortScience 34:350-352.

Reed, B.M. and Y. Chang. 1997. Medium- and longterm storage of in vitro cultures of temperate fruit and nut crops, p. 67-105. In: M.K. Razdan and E.C. Cocking (eds.). Conservation of plant genetic resources in vitro, Vol. 1. Science Publ. Enfield, N.H.

Reed, B.M. and K. Hummer. 1995. Conservation of germplasm of strawberry (Fragaria species), p. 354-370. In: Y.P.S. Bajaj (ed.). Biotechnology in agriculture and forestry, cryopreservation of plant germplasm I, Vol. 32. Springer-Verlag, Berlin.

Vandenbussche, B. and M.P. De Proft. 1998. Cryopreservation of in vitro sugar beet shoot tips using the encapsulation-dehydration technique: Influence of abscisic acid and cold acclimation. Plant Cell Rep. 17:791-793.

Wanas, W.H., J.A. Callow, and L.A. Withers. 1986. Growth limitations for the conservation of pear genotypes, p. 285-290. In: L.A. Withers and P.G. Alderson (eds.). Plant tissue culture and its agricultural applications. Butterworths, London.

Warren, G.J. 1998. Cold stress: Manipulating freezing tolerance in plants. Current Biol. 8:515517.

Weiser, C.J. 1970. Cold resistance and acclimation in woody plants. HortScience 5:403-410.

Wilkins, C.P., H.J. Newbury, and J.H. Dodds. 1988. Tissue culture conservation of fruit trees. FAO/ IBPGR Plant Gen. Res. Newsl. 73/74:9-20. 